\title{
Hybrid Scaffolds Composed of Amino-Acid Coated Sponge and Hydroxyapatite for Hard Tissue Formation by Bone Marrow Cells
}

\author{
Takayoshi Yabuuchi, Masataka Yoshikawa, Hideyuki Kakigi, Hiroyuki Hayashi \\ Department of Endodontics, Osaka Dental University, Osaka City, Japan \\ Email: yabuuchi8@yoshie-gdc.com, yosikawa@cc.osaka-dent.ac.jp, kakigi@cc.osaka-dent.ac.jp, \\ hayashi@cc.osaka-dent.ac.jp
}

Received 1 April 2014; revised 3 May 2014; accepted 11 May 2014

Copyright (C) 2014 by authors and Scientific Research Publishing Inc. This work is licensed under the Creative Commons Attribution International License (CC BY). http://creativecommons.org/licenses/by/4.0/

c) $\underset{\mathrm{EY}}{\mathrm{B}}$ Open Access

\begin{abstract}
A formalin-treated polyvinyl-alcohol (PVF) sponge is convenient as a scaffold because its configuration is easily modified. However, coating the sponge with an adhesive chemical agent is necessary to attach bone marrow cells (BMCs) to the sponge structure. Moreover, it was considered that a hybrid scaffold composed of a sponge and enveloped cylindrical porous hydroxyapatite (HA) would be convenient. In this study, the effect of leucine (Leu) coating on a PVF sponge was examined for osteogenesis on an HA/PVF hybrid scaffold by rat BMCs (rBMCs). In an in vivo assessment, the sponge immersed in Leu solution $(10 \mathrm{mg} / \mathrm{ml})$ was inserted into the hollow center of cylindrical HA. The sponge received $1.5 \times 10^{6}$ rBMCs obtained from male Fischer 344 rats. The hybrid scaffolds were then implanted subcutaneously of syngeneic rats for 6 weeks. In vitro assessment of Leu to hard tissue formation with coating on the well or addition in rBMC culture medium was also performed in a 6-well plate for 2 weeks. In vivo examinations showed the excellent effect of Leu coating on PVF sponge. Leu-coated PVF sponge in the scaffolds showed marked new bone formation in the pores by histological examination. Leu-coated PVF sponge showed a high quantity of osteocalcine (OC). HA might prevent the release of rBMCs from PVF as a barrier. In in vitro examinations, the quantity of $O C$ in rBMC culture with and without the addition of Leu in culture medium showed no significant difference. However, addition of Leu showed significant ALP activity level in culture medium. Leu coating in culture plate wells showed no influence on the quantity of OC. It was concluded from the results that Leu might prevent the emigration of rBMCs to the outside of the scaffold and promote the differentiation of cells to osteoblasts in the scaffold.
\end{abstract}

\section{Keywords}

Amino-Acid, Bone Marrow Cells, Bone Formation, Hybrid Scaffold, Scaffold, Hydroxyapatite, Formalin-Treated Polyvinyl-Alcohol Sponge 


\section{Introduction}

Regeneration of hard tissue is an ideal method to restore partial tooth defects or to replace a missing tooth. The potential of induced pluripotent stem cells (iPS cells) is extremely high for the regeneration of tissue or organs. Tooth regeneration by iPS cells should be studied in dentistry [1] [2]. However, as it is well known, teeth have a specific structure consisting of ectoderm and mesodermal tissue and show a complex configuration. On the right and left sides of the maxilla and mandible, anterior teeth, canines, premolars and molars vary in configuration, respectively. In brief, teeth reveal an individual indigenous complicated configuration. Therefore, it is considered that tooth regeneration by iPS cells may not be realized immediately.

First of all, for tooth regeneration, dentine formation is essential. It is considered that mesenchymal stem cells are required for dentine regeneration in tooth defects and missing the teeth. In addition, a scaffold is needed to regenerate a tooth three-dimensionally. At the level of present tissue engineering, tooth regeneration is impossible. For missing teeth, a structure for the tooth root should be constructed in alveolar bone for the preservation of an artificial crown.

Concerning bone regeneration, in orthopedics, it has been mentioned that porous hydroxyapatite (HA) was effective as a scaffold [3]-[7]. Yoshikawa et al. reported the suitability of porous HA structures as a scaffold in tooth regeneration [8]. It was shown that hard tissue in the pores formed extremely effectively in a cylindrical HA scaffold with a hollow center by rat bone marrow cells (rBMCs). Porous HA should be suitable as a scaffold for tooth regeneration because teeth have an apatitic structure. The configuration of regenerated hard tissue must accord with that of the partial defect of the tooth crown. However, the HA structure is very hard. Therefore, molding the configuration in accordance with the partial defect of the tooth crown would be difficult.

Sponge can be easily adjusted to any configurations as a scaffold. Several insoluble sponges have been produced from polyvinyl-alcohol (PVA) and used in many studies as a scaffold [9]-[11]. Polyvinyl-formal (PVF) sponge made by formalization of PVA is convenient as a scaffold because its configuration is easily modified. However, BMCs may not adhere well from our previous research. The fine structure of the sponge coating as a result of cell adhesive factors may contribute to keeping many rBMCs within the sponge for proliferation and differentiation [12]. It was considered that an HA scaffold with a PVF sponge in the hollow center might be appropriate to reproduce a tooth because such a construction resembles that of a tooth. Therefore, hybrid scaffolds were prepared and used in this study. Furthermore, leucine (Leu) was selected as the cell adhesive agent to improve cell attachment in the PVF sponge in the hollow center of HA scaffolds. Leu coating was performed by immersion of PVF sponges in a Leu solution.

The purpose of this study was to evaluate the effects of Leu on accelerating bone formation in a scaffold. In vitro nodule formation by the effects of Leu was estimated by measuring the quantity of osteocalcine (OC) and alkaline phosphatase (ALP) level in the rBMC culture. The effect of coating Leu on the PVF sponge was evaluated in this in vivo examination, and osteogenesis in the scaffolds was estimated histologically, biochemically and immunochemically. That is to say, the experimental purpose was to examine whether a sponge scaffold immersed in Leu had a marked effect on osteogenesis by rBMCs in the hybrid scaffold.

\section{Materials and Methods}

\subsection{Animals}

This study was performed under the Guidelines for Animal Experimentation at Osaka Dental University. Regarding the use and care of the animals, the Animal Welfare Committee of Osaka Dental University approved the experimental procedures. Male Fischer 344 rats used in this study were kept in standard rat cages with free access to dry pellets and water with unrestricted movement at all times during feeding. All surgical procedures on the animals were performed under general anesthesia by intra-peritoneal injection of sodium pentobarbital (DS Pharma Biomedical Co., Ltd., Osaka, Japan) at a rate of 4 mg per 100 g body weight.

\subsection{Rat Bone Marrow Cell Preparation}

BMCs were taken from the shafts of the femora of 6-week-old male Fischer 344 rats (Clea Japan, Osaka, Japan) after euthanasia by intra-peritoneal injection of an excessive dose of sodium pentobarbital. The cells were flushed out using $10 \mathrm{ml}$ culture medium expelled from a syringe with a 21-gauge needle. Primary culture of the cells was performed for 1 week in a cell culture flask (T-75; BD Biosciences, MA, USA) containing minimum essen- 
tial medium (MEM; Nacalai Tesque, Inc., Kyoto, Japan) supplemented with 15\% fetal bovine serum (FBS; Nichirei Biosciences Inc., Tokyo, Japan) and antibiotics (100 U/ml penicillin, $100 \mathrm{mg} / \mathrm{ml}$ streptomycin and 0.25 $\mathrm{mg} / \mathrm{ml}$ amphotericin B; Sigma-Aldrich Co., MO, USA). The medium was changed 2 times. After primary culture, rBMCs in the T-75 culture flask were washed three times using phosphate buffer solution without $\mathrm{Ca}^{2+}$ and $\mathrm{Mg}^{2+}$ (PBS (-); Nacalai Tesque Inc.) and the cells were isolated from the bottom of the T-75 flask with trypsinEDTA solution $(0.5 \mathrm{mg} / \mathrm{ml}$ trypsin and $0.53 \mu \mathrm{mol}$ EDTA; Nacalai Tesque Inc.) to prepare bone marrow cell suspension. Harvested cells were re-suspended in culture medium at $0.5 \times 10^{5}$ cells $/ \mathrm{ml}$ for an in vitro examination. The other suspension of BMCs at $1 \times 10^{7}$ cells $/ \mathrm{ml}$ concentration was prepared for in vivo examination.

\subsection{Preparation of Experimental Hybrid Scaffolds for in Vivo Examination}

Leu was purchased from the Peptide Institute, Inc. (Osaka, Japan) and dissolved at $100 \mathrm{mM}$ concentration in ultra-purified water. The liquid was sterilized by filtration (Millex ${ }^{\circledR}: 0.22 \mu \mathrm{m}$; Milipore Japan, Tokyo, Japan).

The cylindrical HA structures used in this study (Figure 1) were especially manufactured by Hoya Technosurgical Company (Tokyo, Japan) according to our design. Cylindrical porous HA structures were $8 \mathrm{~mm}$ in diameter and $10 \mathrm{~mm}$ in height with a hollow center measuring $5 \mathrm{~mm}$ in diameter. Total porosity of the structures was 55\%. The diameter of each aperture on the surface of the HA structure was approximately $100-300 \mu \mathrm{m}$. The aperture diameter between interconnected pores was approximately 50 - $300 \mu \mathrm{m}$.

A sheet of PVF sponge made of formalin-treated polyvinyl alcohol was generously donated by Ione Co., Ltd. (Osaka, Japan). PVF sponges were cut cylindrically from the PVF sponge sheet. The cylindrical PVF sponge used as a scaffold in this study (Figure 2) was $5 \mathrm{~mm}$ in diameter and $8 \mathrm{~mm}$ in height. Pore size was $130 \mu \mathrm{m}$ on average. The PVF sponges were sterilized in ethylene oxide gas before immersion in an amino acid solution. A cylindrical HA structure was used to contain the sponge scaffold. The sponges were immersed in Leu solution for 24 hours and these used as a control were immersed in ultra-purified water. The sponges were air-dried under radiation with ultraviolet light. Each of the PVF sponges with and without immersion in Leu solution was respectively placed in the hollow center of HA structures to prepare the novel hybrid scaffold for this study.

For rBMC seeding, a suspension of $150 \mu \mathrm{l}$ at $1 \times 10^{7}$ cells/ml concentration was placed on the PVF sponge in the hybrid scaffold. The number of BMCs seeded in each sponge was $1.5 \times 10^{6}$ cells.

\subsection{In Vivo Estimation of Leu for Bone Formation by rBMCs in Hybrid Scaffolds Implanted in Rat Subcutis}

\subsubsection{Histological Examination}

This in vivo study was performed using 7-week-old male Fischer 344 rats. All procedures were performed under general anaesthesia by intra-peritoneal injection of sodium pentobarbital. The backs of the rats were shaved and disinfected with povidone iodine solution (ISODINE ${ }^{\circledR}$ solution 10\%; Meiji Seika Pharma Co., Ltd., Tokyo, Japan). On the back, along the spinal column, 2 subcutaneous pockets were made on each side. An HA structure, a hybrid scaffold with Leu-coated sponge and rBMC seeding, was inserted into the left subcutaneous pocket and a scaffold without Leu coating but with rBMCs was inserted into the right pocket. The numbers of implanted scaffolds were 6 each. Incised wounds on the back were sutured and then shielded with adhesive (Aron alpha ${ }^{\circledR}$; Toagosei Co., Ltd., Tokyo, Japan).

The scaffolds were removed from the back of animals 6 weeks postoperatively after euthanasia by intra-peritoneal injection of an excess dose of sodium pentobarbital. Three of 6 scaffolds were fixed in $10 \%$ buffered formalin solution and decalcified in $10 \%$ formic acid solution followed by dehydration in ethanol. Then, they were permeated with xylene for embedding in paraffin. The paraffin-embedded specimens were serially cut into $9-\mu \mathrm{m}$-thick sections. Those serial sections were stained with toluidine blue or hematoxylin-eosin alternately for histological examination under an optical microscope.

\subsubsection{Measurement of OC Quantity Immunochemically and ALP Level Biochemically}

The other scaffolds were used for measurement of the ALP level biochemically and quantitative analysis of OC immunochemically. After removal of the scaffolds from the subcutis, they were immediately frozen in liquid nitrogen. Then, they were crushed and homogenized in $1 \mathrm{ml}$ of a 10-fold concentration of TNE buffer solution (pH 7.4; 10 mM Tris-HCl, 1 mM EDTA, 100 mM NaCl) using a Mixer Mill ${ }^{\circledR}$ (MM301; Verder Scientific Co., Ltd., 


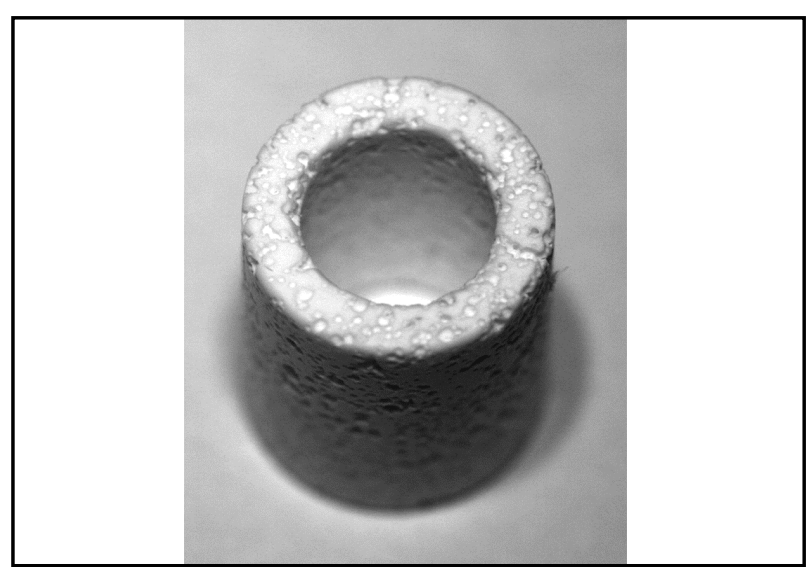

Figure 1. Macro-photographic image of cylindrical porous hydroxyapatite with a hollow center $(10 \mathrm{~mm}$ in height, $8 \mathrm{~mm}$ in outer diameter, and $5 \mathrm{~mm}$ in the hollow center). Total porosity was $55 \%$. The diameter of the aperture between interconnected pores was approximately $50-300 \mu \mathrm{m}$.

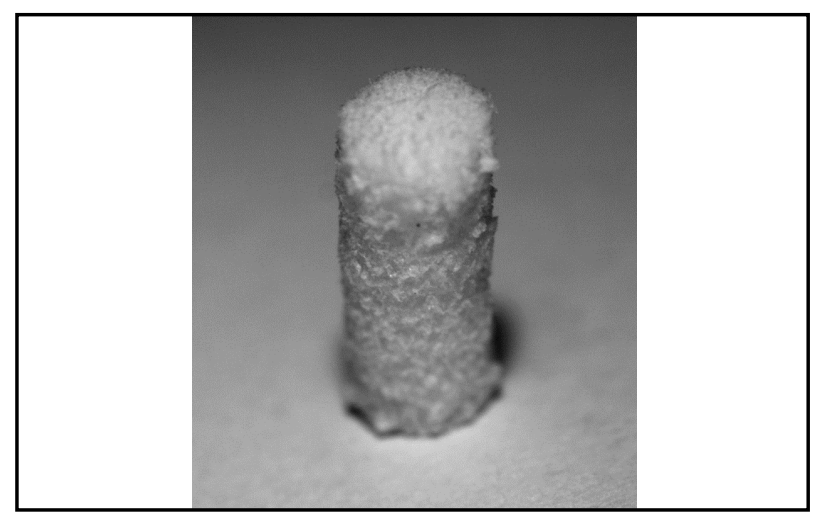

Figure 2. Macro-photographic image of a PVF sponge before insertion in the hollow center of the HA scaffold. The height was $8 \mathrm{~mm}$ and the diameter was $5 \mathrm{~mm}$. Diameter of pores was approximately $130 \mu \mathrm{m}$.

Tokyo, Japan). The homogenized samples were sonicated (BIORUPTOR UCW-201; Tosho Denki Co., Ltd., Yokohama, Japan) for 30 seconds at $3^{\circ} \mathrm{C}$. The emulsified sample was passed through a column (PD-10 desalting column; GE Healthcare UK Ltd., Buckinghamshire, UK) to collect the osteocalcin adhered to HA. Then, each sample was centrifuged for 1 minute at 16,000 $\times$ g. The quantity of ALP in the scaffolds was measured biochemically. The supernatant was reacted with $p$-nitro-phenylphosphate (Zymed Laboratories Inc., CA, USA) as a substrate at $37^{\circ} \mathrm{C}$ for 30 minutes. Absorbance of the reactant was measured at $405 \mathrm{~nm}$. The value of ALP activity is presented per scaffold as $\mu \mathrm{M}$ of $p$-nitrophenol released after 30 minutes of incubation at $37^{\circ} \mathrm{C}$.

For quantitative analysis of OC, the supernatant was also passed through a PD-10 desalting column to collect the osteocalcin from HA to which OC might have adhered. The desalted supernatants were respectively poured into each well of a 96-well micro plate (Rat Osteocalcin ELISA kit DS ${ }^{\circledR}$; DS Pharma Biomedical Co., Ltd.). The bottom of each well was coated with anti-rat OC antibody. Peroxidase-conjugated anti-rat OC polyclonal antibody was added to each well. An equivalent mixture of peroxidase substrate and hydrogen peroxide water was added followed by incubation in the dark. Absorbance of $450 \mathrm{~nm}$ was measured using a spectrophotometer (SpectraMax M5; Molecular Devices Corporation Japan, Tokyo, Japan).

Data are presented as the mean \pm standard deviation. Statistical comparisons between the mean values in implanted scaffolds were performed using two-way unrepeated ANOVA followed by post hoc analysis using the Tukey-Kramer's test. Differences of $p<0.01$ were considered significant. 


\subsection{In Vitro Estimation of the Effects of Leu for Hard Tissue Formation by rBMC Culture}

\subsection{1. rBMCs Culture in Leu-Coated Culture Plate Wells}

For Leu coating on wells in culture plates (6-well culture plate: BD Biosciences), $2 \mathrm{ml}$ Leu solution at $10 \mathrm{mg} / \mathrm{ml}$ concentration was poured to the wells and left for 1 hour at room temperature for air dried. In each well of both Leu-coated 6-well culture plates and uncoated 6-well culture plates as a control, rBMC suspension in $2 \mathrm{ml}$ MEM containing $1 \times 10^{5}$ cells was seeded and cultured for 2 weeks in MEM supplemented with FBS and ABs in an incubator at $5 \% \mathrm{CO}_{2}$ and $95 \%$ relative humidity at $37^{\circ} \mathrm{C}$. To assess rBMCs differentiation and calcified nodule formation in the well with and without Leu coating on the bottom of the culture plate, $10 \mathrm{nM}$ dexamethasone (Dex; Sigma-Aldrich Co.), 1 mM $\beta$-glycerophosphate ( $\beta$-GP; EMD Biosciences, Inc., CA, USA) and $82 \mu \mathrm{g} / \mathrm{ml}$ ascorbic acid (Vc; Sigma-Aldrich Co.) were also added to the culture medium. Only $\beta$-GP was added to the medium for rBMC culture as a control. The medium was replaced 3 times each week.

\subsection{2. rBMCs Culture in the Culture Medium with Addition of a Leu Solution}

To each well of 6-multi-well culture plates (BD Biosciences), $2 \mathrm{ml}$ suspension containing $1 \times 10^{5} \mathrm{rBMCs}$ was added. Subculture was performed for 2 weeks with MEM containing 15\% FBS, $1 \mathrm{mM} \beta$-GP and antibiotics. The medium was replaced three times a week. When MEM in the wells was replaced, $20 \mu$ l Leu solution was added. To promote bone marrow cell differentiation and calcified nodule formation, $10 \mathrm{nM}$ Dex and $82 \mu \mathrm{g} / \mathrm{ml}$ Vc were also added.

\subsubsection{Quantitative Analysis of ALP and OC}

Supernatant in each well of all culture plates was collected after culture for 14 days. For measurement of ALP activity, each subcultured cell layer on the plate was scraped off in $1 \mathrm{ml}$ of a 10-fold concentration of TNE solution (pH 7.4; $10 \mathrm{mM}$ Tris-HCl, $1 \mathrm{mM}$ EDTA, $100 \mathrm{mM} \mathrm{NaCl}$ ). The cells in the buffer solution were homogenized and $0.1 \mathrm{ml}$ sonicated cell suspension was used for DNA measurement. Salmon sperm DNA (Life Technologies Inc., CA, USA) was used as the standard. DNA was measured by fluorescence emission at $460 \mathrm{~nm}$ in the presence of $2.5 \mu \mathrm{g} / \mathrm{ml}$ Hoechst 33258 (Dojindo Laboratories, Kumamoto, Japan). The other sonicated cell suspension was used for measurement of ALP activity. The suspension was centrifuged at 16,000 $\times \mathrm{g}$ for 1 minute. For measurement of ALP activity, $0.1 \mathrm{ml}$-nitrophenyl phosphate (PNP: Zymed Lab.) was added as substrate to 20 $\mu \mathrm{l}$ supernatant and incubated at $37^{\circ} \mathrm{C}$ for 30 minutes. The reaction was stopped by the addition of $100 \mu \mathrm{l} \mathrm{NaOH}$ at $0.2 \mathrm{M}$ concentration. Quantity of $p$-nitrophenol produced by reaction of the supernatant with PNP was determined by measurement of the absorbance at a wavelength of $405 \mathrm{~nm}$. The ALP level of the cultured bone marrow stem cells with and without addition of lysine solution to the culture medium was represented as $\mu \mathrm{M}$ of $p$-nitrophenol released after 30 minutes of incubation at $37^{\circ} \mathrm{C}$. The ALP/DNA ratio was calculated as ALP activity. Quantity of OC in the supernatant from rBMC culture for nodule formation was measured immunochemically using Rat Osteocalcin ELISA kit DS ${ }^{\circledR}$.

These results are shown as the mean and standard deviation. Statistical comparisons between the mean values of ALP activity and quantity of OC were performed using two-way unrepeated ANOVA followed by post hoc analysis using Tukey-Kramer's test. Differences of $p<0.01$ were considered significant.

\section{Results}

\subsection{Histological Images of Bone Formation by Seeded rBMCs in Hybrid Scaffolds after Implantation in Rat Subcutis}

Bone formation was observed in the non-coated sponge in the hybrid scaffold but only minimally (Figure 3(a)). A small number of rBMCs emigrated from the sponge into the surrounding HA structure of the hybrid scaffold. Metachromasia by toluidine blue staining showed bone in the pores between the fibers of the sponge construction (Figure 3(b)). In the pores between the fibers of the sponge construction with Leu coating in the hybrid scaffold, a large area of newly formed bone was recognized on micro-photographic images of the paraffin serial sections (Figure 4(a)). In the specimen stained with toluidine blue, the expression of metachromasia proved the presence of bone clearly in the pores (Figure 4(b)). However, in hybrid scaffolds, the sponge component without Leu coating showed new bone formation in many pores of the scaffolds, as in the hybrid scaffold with the Leu-coated sponge. 


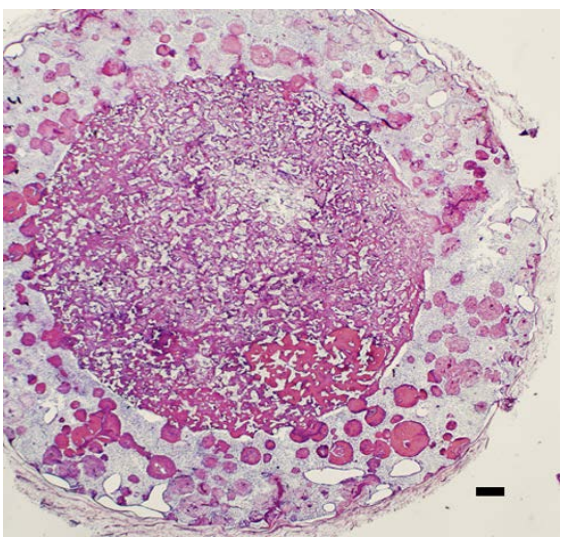

(a)

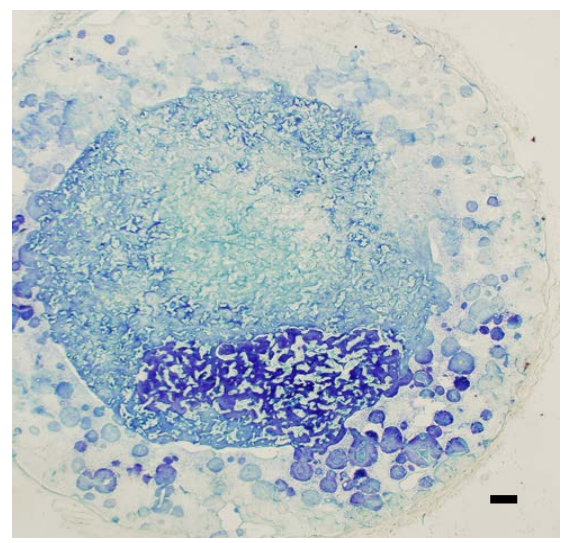

(b)

Figure 3. Micro-photographic image of subcutaneously implanted hybrid scaffold (Bar: 300 $\mu \mathrm{m})$. In the PVF sponge structure, rBMCs were seeded before subcutaneous implantation. (a) Many pores with new bone in the HA structure and in the PVF sponge were found by hematoxylin and eosin staining. (b) Metachromasia was recognized in cells and intercellular substances by toluidine blue staining.

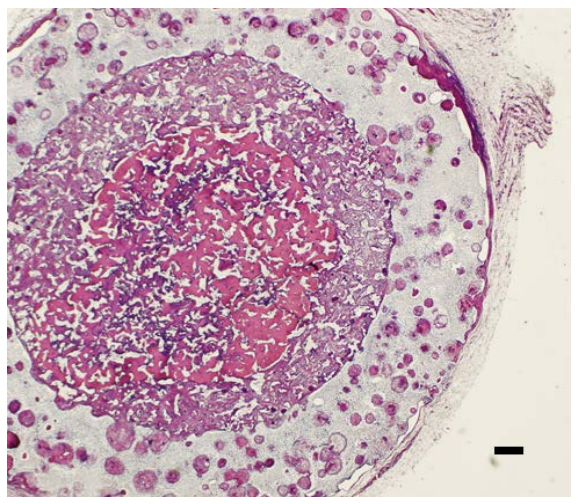

(a)

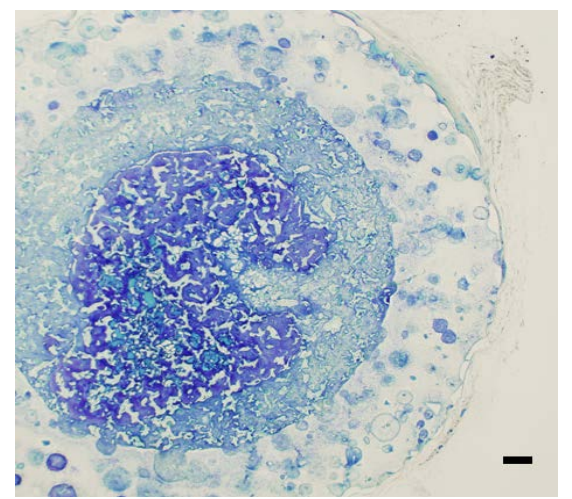

(b)

Figure 4. Micro-photographic image of a paraffin section of a hybrid scaffold (Bar: $300 \mu \mathrm{m})$. In the PVF sponge structure with leucine coating, rBMCs were seeded before subcutaneous implantation. (a) New bone with many pores was seen in the sponge structure. Hematoxylin and eosin staining. (b) In a conspicuously large area of the sponge structure in the hybrid scaffold, metachromasia was recognized. It is clear that many pores of the leucine-coated fibrous structure of PVF sponge contained newly formed bone. Toluidine blue staining.

\subsection{Measurement of ALP and OC in Hybrid Scaffolds with rBMCs after Subcutaneous Implantation}

The quantity of ALP in the scaffold with the Leu-coated PVF sponge was about $121.9 \pm 28.0 \mu \mathrm{M} / \mathrm{scaffold}$. On the other hand, in the scaffold with non-coated PVF sponge, it was approximately $827.5 \pm 111.7 \mu \mathrm{M} / \mathrm{scaffold}$. The quantity of ALP in the hybrid scaffold with Leu-coated sponge was significantly lower than in the control scaffold with non-coated sponge (Figure 5). The hybrid scaffold with Leu-coated PVF sponge showed a large quantity of OC, $13.8 \pm 4.5 \mu \mathrm{g} / \mathrm{scaffold}$. In the scaffold with a non-coated PVF sponge, it was $2.0 \pm 1.4$ $\mu \mathrm{g} / \mathrm{scaffold}$. The value was therefore significantly higher than with the non-coated sponge (Figure 6).

\subsection{In Vitro Estimation of Leu for Hard Tissue Formation in rBMC Culture}

\subsubsection{ALP Activity}

The results of biochemically analyzed ALP activity obtained from rBMC culture are shown in Figure 7. With or without the effects of Leu, ALP activity of rBMCs by the addition of Dex, Vc and $\beta$-GP to culture medium was 


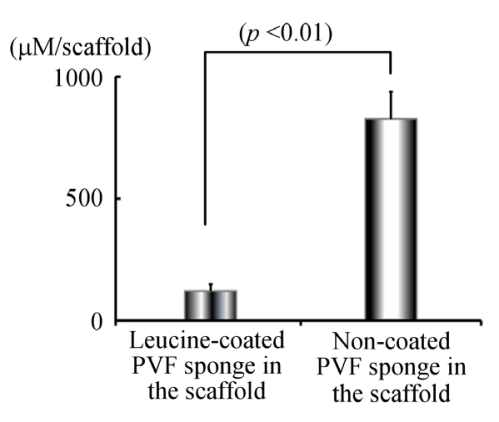

Figure 5. Quantity of ALP in the hybrid scaffolds 6 weeks after subcutaneous implantation. The hybrid scaffold with a noncoated PVF sponge show a significant difference from the hybrid scaffold with a PVF sponge with leucine coating of the fibrous structure $(p<0.01)$. The hybrid scaffolds with a leucinecoated PVF sponge showed a low level of ALP.

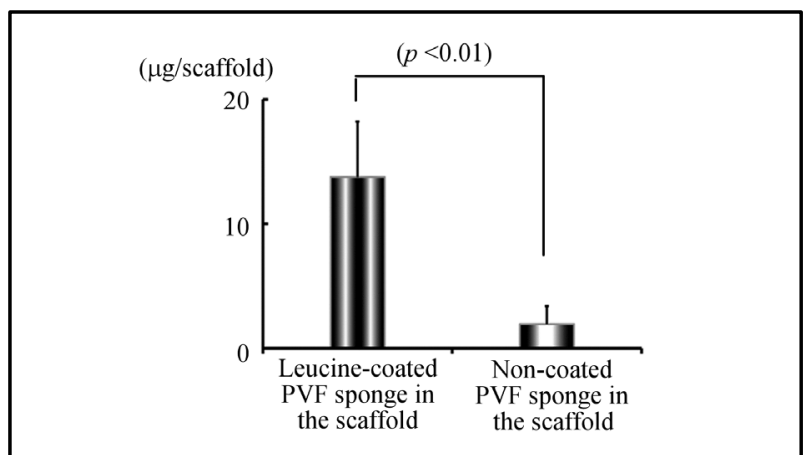

Figure 6. Measurement of the quantity of osteocalcine in the hybrid scaffolds 6 weeks after subcutaneous implantation. Compared to the hybrid scaffolds with a non-coated PVF sponge in the hollow center, a significant large quantity of osteocalcine was measured in hybrid scaffolds with a leucine-coated PVF sponge $(p<0.01)$.

significantly higher than that in the medium with $\beta$-GP only $(p<0.01)$. In Leu-coated wells, the activities were $0.94 \pm 0.02 \mu \mathrm{M} / \mu \mathrm{g}$ DNA with the addition of Dex, Vc and $\beta$-GP and $0.08 \pm 0.02 \mu \mathrm{M} / \mu \mathrm{g}$ DNA with the addition of $\beta$-GP only. In non-coated wells, rBMCs cultured in Leu-added medium with Dex, Vc and $\beta$-GP showed activity of $1.46 \pm 0.11 \mu \mathrm{M} / \mu \mathrm{g}$ DNA. The cells cultured in the medium with Leu and $\beta$-GP showed $1.02 \pm 0.17 \mu \mathrm{M} / \mu \mathrm{g}$ DNA. In non-coated wells, $0.98 \pm 0.26 \mu \mathrm{M} / \mu \mathrm{g}$ DNA was shown in the culture with the addition of Dex, Vc and $\beta$-GP and $0.21 \pm 0.14 \mu \mathrm{M} / \mu \mathrm{g}$ DNA with the addition of $\beta$-GP only. Addition of Leu solution to the culture medium resulted in statistically significant ALP activity by rBMCs $(p<0.01)$. There was no significant difference in the ALP activity level of cultured rBMCs between the culture wells with and without coating by Leu solution ( $p$ $<0.01)$.

\subsubsection{Quantity of $\mathrm{OC}$}

The quantity of OC in rBMC culture medium with Dex, Vc and $\beta$-GP was significantly higher than that in the medium with $\beta$-GP only $(p<0.01$ ). With or without the effects of Leu, the highest quantity of OC in rBMCs was measured in the medium containing Dex, Vc and $\beta$-GP without Leu (Figure 8). The quantity of OC by rBMC culture in the medium with Dex, Vc and $\beta$-GP in Leu-coated wells was $4.40 \pm 1.60 \mu \mathrm{g} / \mathrm{mL}$, and that in Leuadded medium with Dex, Vc and $\beta$-GP was $4.78 \pm 2.70 \mu \mathrm{g} / \mathrm{mL}$. Without the effect of Leu, the quantity of OC was $7.56 \pm 1.95 \mu \mathrm{g} / \mathrm{mL}$ in the medium containing $\beta$-GP. Between these results, no significant difference was obtained $(p<0.01)$. 


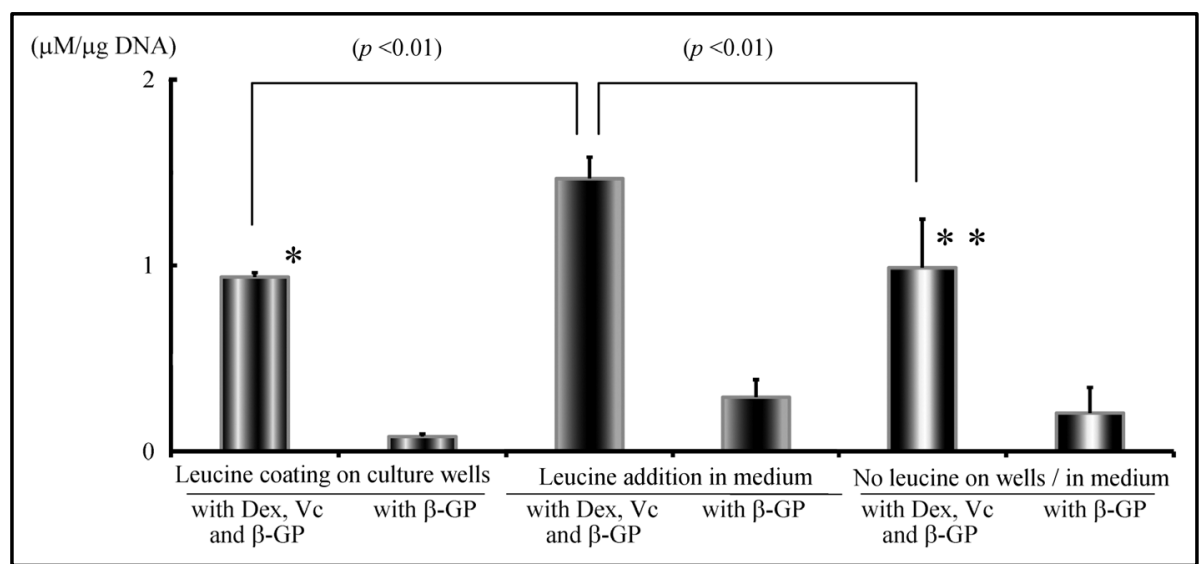

Figure 7. In vitro effects of leucine for hard tissue formation in rBMC culture: Measurement of ALP activity in rBMC culture. With or without leucine coating of culture wells, ALP activity of rBMCs in culture medium was significantly higher by the addition of Dex, Vc and $\beta$-GP than in the medium with $\beta$-GP only $(p<0.01)$. There was no significant difference in the level of ALP between culture wells with and without leucine coating. (N.S.: * vs **). Level of ALP activity in $\mathrm{rBMC}$ culture was significantly increased by the addition of leucine solution to the culture medium.

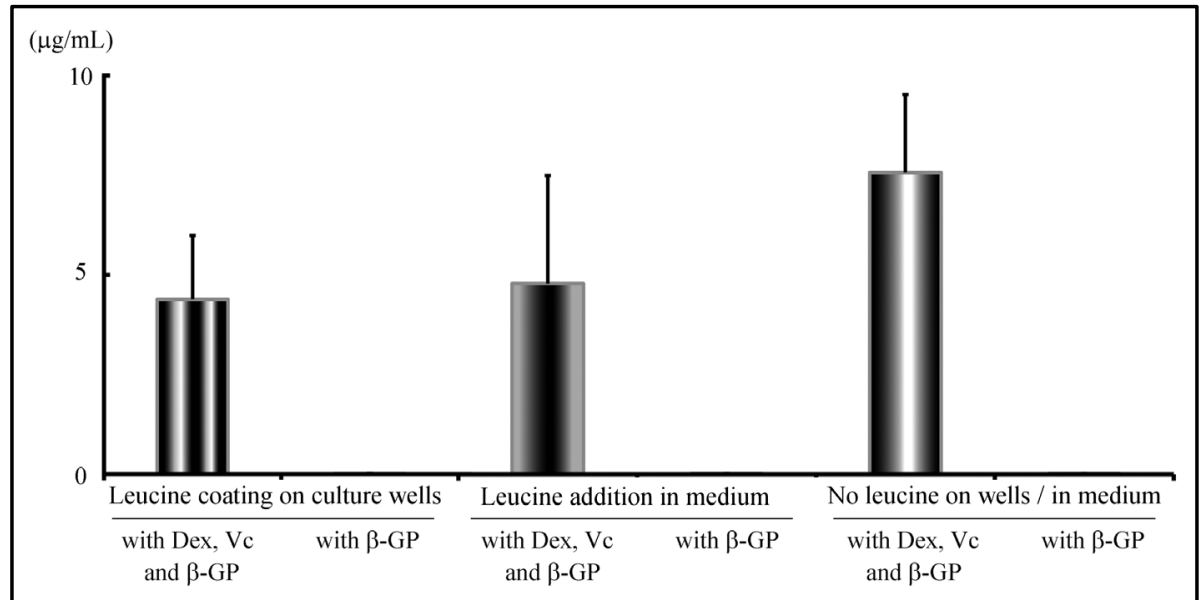

Figure 8. In vitro effects of leucine on hard tissue formation in rBMCs culture: Measurement of $\mathrm{OC}$ in rBMC culture. The quantity of OC in rBMC culture medium with Dex, Vc and $\beta$-GP was significantly higher than in the medium with $\beta$-GP only. With or without the effects of leucine, the highest quantity of OC in rBMCs was measured in the medium containing Dex, Vc and $\beta$-GP. There was no significant difference between the effects of leucine added as leucine solution to the culture medium and leucine coating of culture wells.

\section{Discussion}

Teeth are complex organs containing three separate hard tissues: dentine, enamel and cementum. Cementum attaches to bone via a periodontal ligament. Tooth regeneration by tissue engineering may be particularly difficult because the constitution and configuration of a tooth is complex, as mentioned by Lemus [13]. It was investigated whether new odontoblasts which would differentiate from mesenchymal stem cells in the dental pulp might form new dentine to repair tooth defects [14]. For tooth regeneration, odontoblasts, ameloblasts and cement blasts will play an important role. The isolation of these blast cells from tissue for differentiation into each cell was reported [15]-[18]. A tooth from cultured rat tooth bud cells was also reported [19]. Dental follicle progenitor cells isolated from human third molars have the ability to form calcified nodules [20]. However, the regeneration of a tooth with a three-dimensional configuration will be extremely difficult. For the regeneration of 
a tooth or bone with a three-dimensional structure, the use of a scaffold is preferable for the proliferation and differentiation of stem cells and for regeneration [21]-[24]. Sufficient load resistance is required for regenerated hard tissue, such as a tooth and bone. For the regeneration of load-resistant hard tissue, the use of HA as a scaffold may be appropriate.

Sufficient nutrition supply to the stem cells in the pores and attachment to the pore wall of the cells are essential to promote bone formation in a porous scaffold by the cells [24]. It is also desirable for the scaffold to adapt to any tooth defect shape for restoration. Several types of scaffolds have been reported [24] [25]. The strength of many sponges as a scaffold is extremely low. However, a sponge may be easily adapted to a defect. A PVA sponge with bone marrow cells was used for bone regeneration in a bone defect in a previous study [9]. In this study, a commercially available PVF sponge was used as the scaffold. PVF sponge has a PVA cross-linked construction from the effect of formalin. Marked osteogenesis in the scaffold might be induced by stem cells deposited on the porous scaffold by coating with a chemical agent, which was used as an adhesive [26].

Bone marrow mesenchymal stem cells will differentiate into many cell types, including adipocytes and osteoblasts, depending upon culture conditions [27]. It was reported that bone-like tissue was formed by rat bone marrow cells in vitro. The cells were cultured in MEM supplemented with Dex and $\beta$-GP [28]. In an in vitro culture, bone construction was induced on a porous ceramic framework [29]. It was found that the bone grown by culture possessed high osteogenic capacity in syngeneic rats [30]. In tissue engineering, porous HA is needed and has been used as a scaffold [21]-[23]. In dentistry, resin or metal has been traditionally used as filling material to restore partial defects of the tooth crown with reasonable satisfaction. However, teeth with conspicuous hard tissue defects may have to be extracted. In humans, there is no tertiary dentition. After tooth dislocation or extraction, for recovery of mastication, the lost tooth should be replaced by a bridge, denture or an implanted tooth. However, for aesthetic or functional reasons, not all patients will be satisfied with a prosthesis using these methods. Regenerated teeth including the periodontal tissue are the ultimately ideal. In the future in dentistry, regeneration of a tooth defect or lost teeth by tissue engineering is desirable as a prosthetic method. It is considered that a long time and study will be necessary until tooth regeneration is realized and applied clinically because of the difficulty of tooth regeneration by tissue engineering.

Tooth initiation and morphogenesis occur by the combination of many genes and epigenetic factors [31] [32]. Each tooth matures through four phases morphologically, which are initiation, bud, cap, and cell stages [33]. By passing through these stages, a tooth with a complex configuration is formed, consisting of ectoderm and mesenchymal tissues. It was reported that a structure similar to a mature tooth, including dentine, enamel, cementum and pulp, was induced from a tooth germ in vitro [34]. In regard to tooth regeneration, many studies have been performed [35]-[38]. Teeth must be regenerated with a three-dimensional configuration. Generally, cells are cultured in a monolayer. The regeneration of hard tissue by three-dimensional cell culture would therefore be difficult, so a scaffold would be suitable for tooth regeneration. The ultrastructure of a tooth constructed from hard tissue resembles bone. HA resembles the inorganic ingredient of bones and teeth. Therefore, at a fundamental level, the process of tooth regeneration constructed from hard tissue might be the same as that of bone [39] [40]. It has been agreed in many studies that an HA scaffold was effective for dentin or dentin pulp composite regeneration [41]-[43]. We consider that it would be an ideal method to regenerate a tooth using a cylindrical scaffold [24]. Osteogenesis due to stem cells in the HA was excellent in this and our previous studies [24] [41].

A tooth for biological replacement must be functional with roots and a periodontal ligament. It is desirable for the tooth to include a nerve and blood supply in the pulp canal. Dental pulp in the center of a tooth is surrounded by dentine. Dentine in the tooth crown is coated by enamel and dentine in the tooth root is coated by cementum. The most suitable configuration of a scaffold for regeneration of the dentine-pulp complex is cylindrical with a hollow center, as used in our previous studies [24] [41]. It is desirable for connective tissue, which proliferates in the hollow center of the scaffold to include undifferentiated stem cells or odontoblast-like cells. Regarding tooth regeneration, one of the definitive goals is the regeneration of pulp, the dentin composite. Therefore, the reproduction of pulp tissue will be required in the hollow. It was clear from the results of our previous study [24] that the configuration of a cylindrical HA scaffold might be suitable for hard tissue formation in the scaffold by BMCs. On the other hand, a sponge scaffold may also be suitable for hard tissue formation [9]-[12]. However, the fine structures of porous HA and the sponge are different. Treating the scaffold with an adhesive might be required for BMC attachment to use the sponge as a scaffold [12]. Leu was selected in this study because it might affect bone formation, according to past reports [44]-[46]. For example, Leu residue in a protein may affect the action of BMCs on mineralized nodule formation. 
Generally, in a porous HA scaffold, bone formation by stem cells occurs under certain conditions. In an HA scaffold with a hollow center, Yoshikawa et al. reported previously that bone was formed in a marked number of pores by seeded BMCs [24] [41]. In this in vivo study, cylindrical HA structures with a columnar PVF sponge in the hollow center were used as a scaffold. rBMCs were seeded in the PVF sponge. Some rBMCs infiltrated the outside structural HA and osteogenesis was observed in the pores of HA. From the histologic findings of bone formation in the pores, infiltration of rBMCs into the HA structure of the hybrid scaffold was suggested. Marked osteogenesis was indicated in the hybrid scaffold with Leu-coated PVF sponge in this study. Quantitative analysis of OC also showed significant differences in the scaffold with Leu-coated PVF sponge. It was clear from the results of this study that Leu coating of the PVF sponge scaffold greatly contributed to the osteogenesis by rBMCs seeded in the hybrid scaffold. Osteogenesis in PVF sponge was evaluated in a previous in vivo study [12]. Because the sizes of the sponges were different, comparison of the results might be inaccurate. From the findings of this in vivo experiment, it was found that Leu coating was effective for osteogenesis. However, no effect was shown on a culture plate coated with Leu. The level of ALP activity of rBMCs revealed on increase by the addition of Leu solution to the culture medium. Huttunen et al. said that the in vitro effect of bioactive tri-peptide, which consists of leucine-lysine-proline, was estimated for osteoblast proliferation, and differentiation from bone marrow-derived mesenchymal stem cells to osteoblasts was recognized [47]. It was also reported that glucocorticoid-induced Leu zipper in mouse MSCs increases ALP activity and enhances mineralized bone nodule formation [48]. This proteoglycan is secreted after formation and is present in the extracellular matrix. There is substantial evidence to support its role in increasing in BMC differentiation and proliferative activity [49]. Small Leu-rich proteoglycan is highly expressed in bone. Biglycan, a small Leu-rich repeat proteoglycan in a variety of extracellular matrix tissues, including bone, cartilage and tendons, plays an important role in bone formation and absorption [50] [51]. It is involved in osteoblast differentiation, collagen fibril formation, morphology, and osteogenesis following marrow ablation. During matrix mineralization, collagen, bone sialoprotein and other proteins secreted from osteoblast cells into the matrix are important for forming mineralization deposits [52].

In this study, Leu residue adhering to the sponge played a strong role in osteogenesis. The influence of Leu on osteogenesis in an in vivo experiment was clearly shown by the level of ALP activity and quantity of OC in the hybrid scaffolds. As mentioned in many studies on proteoglycan, Leu residue included in proteoglycan contributed to osteogenesis. Adhesion of stem cells to the inner structure of PVF is essential for the cells to induse osteogenesis through proliferation and differentiation. Leu does not promote the adhesion of cells in the scaffolds as fibronectin does [47] [53]. However, Leu is an essential amino acid and may act as a cell adhesive agent, having no effect on the cells in the culture. It was reported that intercellular adhesion involves direct binding by cell adhesion molecules in an extracellular matrix or cell membrane. The cells are activated by stimulus from cytokines and adhesive high polymer and adhere to the surface of the scaffold [54]-[57]. It was considered that, by coating the inner structures of PVF with a highly cytotropic substance, adhesion of seeded stem cells might be enabled. In the previous study, osteogenesis in dextran-coated PVF sponges was found in the definitive range in the sponge [12]. In this study, the substance used was Leu. In this in vitro study, no evidence on the induction of calcium deposition by Leu was recognized. However, in this in vivo study, marked osteogenesis in a sponge scaffold treated with Leu was indicated from the quantity of OC estimated by immunochemical analysis. It was also reported by Yoshikawa et al. that the hollow center of the HA scaffold plays an important role to supply nutrition to BMCs in the pores of the HA scaffold [24] [41]. PVF sponge itself in this in vivo study might act as the pathway to deliver nutrition to the cells in the sponge.

In the scaffold used in this study, there was no boundless proliferation of rBMCs; that is to say, generally, marked osseous formation by rBMCs does not occur in the scaffolds. It was found that the quantity of OC measured in the hybrid scaffold after subcutaneous implantation in this study significantly increased in the scaffold with a Leu-coated sponge, whereas the quantity of ALP in the scaffold measured at the same time was significantly smaller. It was supposed that the activity of rBMCs decreased after the osteogenic effect in the scaffold. rBMCs seeded in the scaffold showed no excessive proliferation in the pores of the scaffold. As a result, a small amount of ALP was detected in the scaffold.

Leu acts as an adhesive agent for the cells seeded in the scaffold. The marked osteogenesis by rBMCs seeded in the PVF sponge of the hybrid scaffold was thought to be attributed to the cylindrical HA structure of the PVF sponge and Leu coating of the sponge. According to the results of histologic examination in this in vivo experiment, it was particularly apparent that Leu coating of fibers of the PVF sponge in the hybrid scaffold induced 
marked bone formation in the sponge. Leu contributes considerably to osteogenesis by coating fibers in the PVF sponge.

\section{Conclusions}

It was concluded in this study that Leu plays an important role in the sponge component of the hybrid scaffold for bone formation by coating the fine structure.

The results of this in vivo examination showed the induction of a large quantity of new bone in sponge located in the middle of the hybrid scaffold by rBMCs. Leu acts as an adhesive and irritating chemical agent of rBMCs for bone formation. The effect was indicated by coating the fibers of the PVF sponge in the hybrid scaffold in this study. The HA structure, which surrounded the sponge in the hybrid scaffold, played an important role in inhibiting rBMC release from the PVF sponge.

\section{Acknowledgements}

This study was performed in the Morphological Research Facilities, Biomaterials Research Facilities, LowTemperature Facilities, Tissue Culture Facilities, Laboratory Animal Facilities and Photograph-Processing Facilities, Institute of Dental Research, Osaka Dental University. This study was supported in part by 2008-2010 (C: 20592246), 2011-2013 (C: 23592820) and 2012-2014 (C: 24592889) Grants-in-Aid for Scientific Research

(C) from the Japan Society for the Promotion of Science.

\section{References}

[1] Wen, Y., Wang, F., Zhang, W., Li, Y., Yu, M., Nan, X., Chen, L., Yue, W., Xu, X. and Pei, X. (2012) Application of Induced Pluripotent Stem Cells in Generation of a Tissue-Engineered Tooth-Like Structure. Tissue Engineering: Part A, 18, 1677-1685. http://dx.doi.org/10.1089/ten.tea.2011.0220

[2] Mallon, B.S., Hamilton, R.S., Kozhich, O.A., Johnson, K.R., Fann, Y.C., Rao, M.S. and Robey, P.G. (2014) Comparison of the Molecular Profiles of Human Embryonic and Induced Pluripotent Stem Cells of Isogenic Origin. Stem Cell Research, 12, 376-386. http://dx.doi.org/10.1016/j.scr.2013.11.010

[3] Mastrogiacomo, M., Muraglia, A., Komlev, V., Peyrin, F., Rustichelli, F., Crovace, A. and Cancedda. R. (2005) Tissue Engineering of Bone: Search for a Better Scaffold. Orthodontics \& Craniofacial Research, 8, 277-284.

http://dx.doi.org/10.1111/j.1601-6343.2005.00350.x

[4] Ohgushi, H., Kotobuki, N., Funaoka, H., Machida, H., Hirose, M., Tanaka, Y. and Takakura, Y. (2005) Tissue Engineered Ceramic Artificial Joint-Ex Vivo Osteogenic Differentiation of Patient Mesenchymal Cells on Total Ankle Joints for Treatment of Osteoarthritis. Biomaterials, 26, 4654-4661.

http://dx.doi.org/10.1016/j.biomaterials.2004.11.055

[5] Okamoto, M., Dohi, Y., Ohgushi, H., Shimaoka, H., Ikeuchi, M., Matsushima, A., Yonemasu, K. and Hosoi, H. (2006) Influence of the Porosity of Hydroxyapatite Ceramics on in Vitro and in Vivo Bone Formation by Cultured Rat Bone Marrow Stromal Cells. Journal of Materials Science Materials in Medicine, 17, 327-336. http://dx.doi.org/10.1007/s10856-006-8232-z

[6] Appleford, M.R., Oh, S., Oh, N. and Ong, J.L. (2009) In Vivo Study on Hydroxyapatite Scaffolds with Trabecular Architecture for Bone Repair. Journal of Biomedical Materials Research Part A, 89A, 1019-1027. http://dx.doi.org/10.1002/jbm.a.32049

[7] Herath, H.M., Di Silvio, L. and Evans, J.R. (2010) Biological Evaluation of Solid Free Formed, Hard Tissue Scaffolds for Orthopedic Applications. Journal of Applied Biomaterials \& Functional Materials, 8, 89-96.

[8] Yoshikawa, M., Tsuji, N., Toda, T. and Ohgushi, H. (2007) Osteogenic Effect of Hyaluronic Acid Sodium Salt in the Pores of a Hydroxyapatite Scaffold. Materials Science and Engineering: C, 27, 220-226. http://dx.doi.org/10.1016/j.msec.2006.05.014

[9] Jeong, W.K., Oh, S.H., Lee, J.H. and Im, G.I. (2008) Repair of Osteochondral Defects with a Construct of Esenchymal Stem Cells and a Polydioxanone/Poly (Vinyl Alcohol) Scaffold. Biotechnology and Applied Biochemistry, 49, $155-164$. http://dx.doi.org/10.1042/BA20070149

[10] Charlton, D.C., Peterson, M.G., Spiller, K., Lowman, A., Torzilli, P.A. and Maher, S.A. (2008) Semi-Degradable Scaffold for Articular Cartilage Replacement. Tissue Engineering: Part A, 14, 207-213. http://dx.doi.org/10.1089/ten.a.2006.0344

[11] Thomas, L.V., Arun, U., Remya, S. and Nair, P.D. (2009) A Biodegradable and Biocompatible PVA-Citric Acid Polyester with Potential Applications as Matrix for Vascular Tissue Engineering. Journal Materials Science: Materials in 
Medicine, 20, S259-S269. http://dx.doi.org/10.1007/s10856-008-3599-7

[12] Yoshikawa, M., Tsuji, N., Kakigi, H., Yabuuchi, T., Shimomura, Y., Hayashi, H. and Ohgushi, H. (2010) Dextran Coating on and among Fibers of Polymer Sponge Scaffold for Osteogenesis by Bone Marrow Cells in Vivo. Journal of Biomedical Science \& Engineering, 3, 751-757. http://dx.doi.org/10.4236/jbise.2010.38100

[13] Lemus, D. (1995) Contributions of Heterospecific Tissue Recombinations to Odontogenesis. The International Journal of Developmental Biology, 39, 291-297.

[14] Smith, A.J. and Lesot, H. (2001) Induction and Regulation of Crown Dentinogenesis: Embryonic Events as a Template for Dental Tissue Repair? Critical Reviews in Oral Biology \& Medicine, 12, 425-437. http://dx.doi.org/10.1177/10454411010120050501

[15] Gronthos, S., Brahim, J., Li, W., Fisher, L.W., Cherman, N., Boyde, A., DenBesten, P., Robey, P.G. and Shi, S. (2002) Stem Cell Properties of Human Dental Pulp Stem Cells. Journal of Dental Research, 81, 531-535. http://dx.doi.org/10.1177/154405910208100806

[16] Jo, Y.Y., Lee, H.J., Kook, S.Y., Choung, H.W., Park, J.Y., Chung, J.H., Choung, Y.H., Kim, E.S., Yang, H.C. and Choung, P.H. (2007) Isolation and Characterization of Postnatal Stem Cells from Human Dental Tissues. Tissue Engineering, 13, 767-773. http://dx.doi.org/10.1089/ten.2006.0192

[17] Huang, G.T., Gronthos, S. and Shi, S. (2009) Mesenchymal Stem Cells Derived from Dental Tissues vs. Those from Other Sources: Their Biology and Role in Regenerative Medicine. Journal of Dental Research, 88, 792-806. http://dx.doi.org/10.1177/0022034509340867

[18] Balic, A., Aguila, H.L., Caimano, M.J., Francone, V.P. and Mina, M. (2010) Characterization of Stem and Progenitor Cells in the Dental Pulp of Erupted and Unerupted Murine Molars. Bone, 46, 1639-1651. http://dx.doi.org/10.1016/j.bone.2010.02.019

[19] Duailibi, M.T., Duailibi, S.E., Young, C.S., Bartlett, J.D., Vacanti, J.P. and Yelick, P.C. (2004) Bioengineered Teeth from Cultured Rat Tooth Bud Cells. Journal of Dental Research, 83, 523-528. http://dx.doi.org/10.1177/154405910408300703

[20] Lin, N.H., Gronthos, S. and Bartold, P.M. (2008) Stem Cells and Periodontal Regeneration. Australian Dental Journal, 53, 108-121. http://dx.doi.org/10.1111/j.1834-7819.2008.00019.x

[21] Inoue, K., Ohgushi, H., Yoshikawa, T., Okumura, M., Sempuku, T., Tamai, S. and Dohi, Y. (1997) The Effect of Aging on Bone Formation in Porous Hydroxyapatite: Biochemical and Histological Analysis. Journal of Bone and Mineral Research, 12, 989-994. http://dx.doi.org/10.1359/jbmr.1997.12.6.989

[22] Toquet, J., Rohanizadeh, R., Guicheux, J., Couillaud, S., Passuti, N., Daculsi, G. and Heymann, D. (1999) Osteogenic Potential in Vitro of Human Bone Marrow Cells Cultured on Macroporous Biphasic Calcium Phosphate Ceramic. Journal of Biomedical Materials Research, 44, 98-108. http://dx.doi.org/10.1002/(SICI)1097-4636(199901)44:1<98::AID-JBM11>3.0.CO;2-P

[23] Livingston, T., Ducheyne, P. and Garino, J. (2002) In Vivo Evaluation of a Bioactive Scaffold for Bone Tissue Engineering. Journal of Biomedical Materials Research, 62, 1-13. http://dx.doi.org/10.1002/jbm.10157

[24] Yoshikawa, M., Tsuji, N., Shimomura, Y., Hayashi, H. and Ohgushi, H. (2008) Osteogenesis Depending on Geometry of Porous Hydroxyapatite Scaffolds. Calcified Tissue International, 83, 139-145. http://dx.doi.org/10.1007/s00223-008-9157-y

[25] Young, C.S., Terada, S., Vacanti, J.P., Honda, M., Bartlett, J.D. and Yelick, P.C. (2002) Tissue Engineering of Complex Tooth Structures on Biodegradable Polymer Scaffolds. Journal of Dental Research, 81, 695-700. http://dx.doi.org/10.1177/154405910208101008

[26] Chang, Y.S., Oka, M., Kobayashi, M., Gu, H.O., Li, Z.L., Nakamura, T. and Ikada, Y. (1996) Significance of Interstitial Bone Ingrowth under Load-Bearing Conditions: A Comparison between Solid and Porous Implant Materials. Biomaterials, 17, 1141-1148. http://dx.doi.org/10.1016/0142-9612(96)85917-5

[27] Gimble, J.M., Zvonic, S., Floyd, Z.E., Kassem, M. and Nuttall, M.E. (2006) Playing with Bone and Fat. Journal of Cellular Biochemistry, 98, 251-266. http://dx.doi.org/10.1002/jcb.20777

[28] Maniatopoulos, C., Sodek, J. and Melcher, A.H. (1988) Bone Formation in Vitro by Stromal Cells Obtained from Bone Marrow of Young Adult Rats. Cell and Tissue Research, 254, 317-330. http://dx.doi.org/10.1007/BF00225804

[29] Yoshikawa, T., Ohgushi, H. and Tamai, S. (1996) Immediate Bone Forming Capability of Prefabricated Osteogenic Hydroxyapatite. Journal of Biomedical Materials Research, 32, 481-492. http://dx.doi.org/10.1002/(SICI)1097-4636(199611)32:3<481::AID-JBM23>3.0.CO;2-I

[30] Yoshikawa, T., Ohgushi, H., Dohi, Y. and Davies, J.E. (1997) Viable Bone Formation in Porous Hydroxyl Apatite: Marrow Cell-Derived in Vitro Bone on the Surface of Ceramics. Bio-Medical Materials and Engineering, 7, 49-58.

[31] Jemvall, J. and Thesleff, I. (2000) Reiterative Signaling and Patterning during Mammalian Tooth Morphogenesis. Me- 
chanisms of Development, 92, 19-29. http://dx.doi.org/10.1016/S0925-4773(99)00322-6

[32] Koussoulakou, D.S., Margaritis, L.H. and Koussoulakos, S.L. (2009) A Curriculum Vitae of Teeth: Evolution, Generation, Regeneration. International Journal of Biological Sciences, 5, 226-243. http://dx.doi.org/10.7150/ijbs.5.226

[33] Tucker, A. and Sharpe, P. (2004) The Cutting-Edge of Mammalian Development; How the Embryo Makes Teeth. Nature Reviews Genetics, 5, 499-508. http://dx.doi.org/10.1038/nrg1380

[34] Zhang, W., Walboomers, X.F., Van Kuppevelt, T.H., Daamen, W.F., Van Damme, P.A., Bian, Z. and Jansen, J.A. (2008) In Vivo Evaluation of Human Dental Pulp Stem Cells Differentiated towards Multiple Lineages. Journal of Tissue Engineering and Regenerative Medicine, 2, 117-125. http://dx.doi.org/10.1002/term.71

[35] Yen, A.H. and Sharpe, P.T. (2006) Regeneration of Teeth Using Stem Cell-Based Tissue Engineering. Expert Opinion on Biological Therapy, 6, 9-16. http://dx.doi.org/10.1517/14712598.6.1.9

[36] Morsczeck, C., Schmalz, G., Reichert, T.E., Völlner, F., Galler, K. and Driemel, O. (2008) Somatic Stem Cells for Regenerative Dentistry. Clinical Oral Investigations, 12, 113-118. http://dx.doi.org/10.1007/s00784-007-0170-8

[37] Nosrat, A., Li, K.L., Vir, K., Hicks, M.L. and Fouad, A.F. (2013) Is Pulp Regeneration Necessary for Root Maturation? Journal of Endodontics, 39, 1291-1295. http://dx.doi.org/10.1016/j.joen.2013.06.019

[38] Steindorff, M.M., Lehl, H., Winkel, A. and Stiesch, M. (2014) Innovative Approaches to Regenerate Teeth by Tissue Engineering. Archives of Oral Biology, 59, 158-166. http://dx.doi.org/10.1016/j.archoralbio.2013.11.005

[39] Tan, X.W., Perera, A.P., Tan, A., Tan, D., Khor, K.A., Beuerman, R.W. and Mehta, J.S. (2011) Comparison of Candidate Materials for a Synthetic Osteo-Odonto Keratoprosthesis Device. Investigative Ophthalmology \& Visual Science, 52, 21-29. http://dx.doi.org/10.1167/iovs.10-6186

[40] Zhang, W., Walboomers, X.F., van Osch, G.J., van den Dolder, J. and Jansen, J.A. (2008) Hard Tissue Formation in a Porous HA/TCP Ceramic Scaffold Loaded with Stromal Cells Derived from Dental Pulp and Bone Marrow. Tissue Engineering Part A, 14, 285-294. http://dx.doi.org/10.1089/tea.2007.0146

[41] Yoshikawa, M., Tsuji, N., Shimomura, Y., Hayashi, H. and Ohgushi, H. (2007) Effects of Laminin for Osteogenesis in Porous Hydroxyapatite. Macromolecular Symposia, 253, 172-178. http://dx.doi.org/10.1002/masy.200750724

[42] Mastrangelo, F., Nargi, E., Carone, L., Dolci, M., Caciagli, F., Ciccarelli, R., De Lutiis, M.A., Karapanou, V., Shaik, B.Y., Conti, P. and Teté, S.J. (2008) Tridimensional Response of Human Dental Follicular Stem Cells onto a Synthetic Hydroxyapatite Scaffold. Journal of Health Science, 54, 154-161. http://dx.doi.org/10.1248/jhs.54.154

[43] Hayakawa, S., Li, Y., Tsuru, K., Osaka, A., Fujii, E. and Kawabata, K. (2009) Preparation of Nanometer-Scale Rod Array of Hydroxyapatite Crystal. Acta Biomaterialia, 5, 2152-2160. http://dx.doi.org/10.1016/j.actbio.2009.02.018

[44] Bi, Y., Stuelten, C.H., Kilts, T., Wadhwa, S., Iozzo, R.V., Robey, P.G., Chen, X.D. and Young, M.F. (2005) Extracellular Matrix Proteoglycans Control the Fate of Bone Marrow Stromal Cells. The Journal of Biological Chemistry, 280, 30481-30489. http://dx.doi.org/10.1074/jbc.M500573200

[45] Warotayanont, R., Zhu, D., Snead, M.L. and Zhou, Y. (2008) Leucine-Rich Amelogenin Peptide Induces Osteogenesis in Mouse Embryonic Stem Cells. Biochemical and Biophysical Research Communications, 367, 1-6. http://dx.doi.org/10.1016/j.bbrc.2007.12.048

[46] Wen, X., Cawthorn, W.P., MacDougald, O.A., Stupp, S.I., Snead, M.L. and Zhou, Y. (2011) The Influence of LeucineRich Amelogenin Peptide on MSC Fate by Inducing Wnt10b Expression. Biomaterials, 32, 6478-6486. http://dx.doi.org/10.1016/j.biomaterials.2011.05.045

[47] Chen, C.H., Yeh, M.L., Geyer, M., Wang, G.J., Huang, M.H., Heggeness, M.H., Höök, M. and Luo, Z.P. (2006) Interactions between Collagen IX and Biglycan Measured by Atomic Force Microscopy. Biochemical and Biophysical Research Communications, 339, 204-208. http://dx.doi.org/10.1016/j.bbrc.2005.10.205

[48] Huttunen, M.M., Pekkinen, M., Ahlström, M.E. and Lamberg-Allardt, C.J. (2007) Effects of Bioactive Peptides Isoleucine-Proline-Proline (IPP), Valine-Proline-Proline (VPP) and Leucine-Lysine-Proline (LKP) on Gene Expression of Osteoblasts Differentiated from Human Mesenchymal Stem Cells. British Journal of Nutrition, 98, 780-788. http://dx.doi.org/10.1017/S0007114507744434

[49] Zhang, W., Yang, N. and Shi, X.M. (2008) Regulation of Mesenchymal Stem Cell Osteogenic Differentiation by Glucocorticoid-Induced Leucine Zipper (GILZ). The Journal of Biological Chemistry, 283, 4723-4729. http://dx.doi.org/10.1074/jbc.M704147200

[50] Waddington, R.J., Roberts, H.C., Sugars, R.V. and Schönherr, E. (2003) Differential Roles for Small Leucine-Rich Proteoglycans in Bone Formation. European Cells \& Materials, 6, 12-21.

[51] Chen, X.D., Allen, M.R., Bloomfield, S., Xu, T. and Young, M. (2003) Biglycan-Deficient Mice Have Delayed Osteogenesis after Marrow Ablation. Calcified Tissue International, 72, 577-582. http://dx.doi.org/10.1007/s00223-002-1101-y

[52] Bi, Y., Nielsen, K.L., Kilts, T.M., Yoon, A., Karsdal, M.A., Wimer, H.F., Greenfield, E.M., Heegaard, A.M. and 
Young, M.F. (2006) Biglycan Deficiency Increases Osteoclast Differentiation and Activity Due to Defective Osteoblasts. Bone, 38, 778-786. http://dx.doi.org/10.1016/j.bone.2005.11.005

[53] Wallace, J.M., Rajachar, R.M., Chen, X.D., Shi, S., Allen, M.R., Bloomfield, S.A., Les, C.M., Robey, P.G, Young, M.F. and Kohn, D.H. (2006) The Mechanical Phenotype of Biglycan-Deficient Mice Is Bone- and Gender-Specific. Bone, 39, 106-116. http://dx.doi.org/10.1016/j.bone.2005.12.081

[54] Cool, S.M. and Nurcombe, V. (2005) Substrate Induction of Osteogenesis from Marrow-Derived Mesenchymal Precursors. Stem Cells and Development, 14, 632-642. http://dx.doi.org/10.1089/scd.2005.14.632.

[55] Costa-Pinto, A.R., Correlo, V.M., Sol, P.C., Bhattacharya, M., Charbord, P., Delorme, B., Reis, R.L. and Neves, N.M. (2009) Osteogenic Differentiation of Human Bone Marrow Mesenchymal Stem Cells Seeded on Melt Based Chitosan Scaffolds for Bone Tissue Engineering Applications. Biomacromolecules, 10, 2067-2073. http://dx.doi.org/10.1021/bm9000102.

[56] Zajaczkowski, M.B., Cukierman, E., Galbraith, C.G. and Yamada, K.M. (2003) Cell-Matrix Adhesions on Poly (Vinyl Alcohol) Hydrogels. Tissue Engineering, 9, 525-533. http://dx.doi.org/10.1089/107632703322066705

[57] Tsuji, Y., Yoshimura, N., Aoki, H., Sharov, A.A., Ko, M.S., Motohashi, T. and Kunisada, T. (2008) Maintenance of Undifferentiated Mouse Embryonic Stem Cells in Suspension by the Serum- and Feeder-Free Defined Culture Condition. Developmental Dynamics, 237, 2129-2138. http://dx.doi.org/10.1002/dvdy.21617 